\title{
COVID-19 the intruder: A brief philosophical reflection on strangeness and hospitality
}

\section{Ana Maria Munar and Adam Doering}

Dr Ana María Munar is an Associate Professor at Copenhagen Business School, Denmark, and Honorary Adjunct Professor at Auckland University of Technology, New Zealand. Her research applies philosophical approaches to tourism, hospitality, gender and higher education.

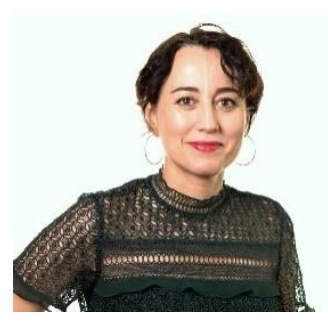

Dr Adam Doering is an Associate Professor of Tourism Studies at Wakayama University, Japan. His current research areas include the philosophy and ethics of hospitality and tourism, cultural politics of lifestyle sports and the role of destination management organisations in Japan's rapidly changing tourism industry.
Some strangers are expected, and some are unexpected. We were experts on the expected ones. Hospitality had developed as the art of expectation and reception. We knew how to receive the guests so they would feel away but at home. We had tamed strangeness out of the stranger and categorised them into an identity that would fit our need of control of the future, of life - the tourist/consumer/guest. We were proud to know the guests as much or even better than ourselves. We knew how to measure them, manage their encounters, tailor their experiences, match their wishes. We were the industry that showed to the world there was nothing to fear from the stranger. We had turned a radical revolutionary arrival, the promise and challenge of meeting otherness into a commercial opportunity, into a well-choreographed ritual.

Then the unexpected stranger arrived in the form of a virus that was as expansive as our wildest dreams of smart fluid mobilities. Only this time, the stranger did not serve the hospitable gaze, the awakening of the senses; instead it brings death. COVID-19 insists on not being welcomed or tamed. It has not yet learned to be one of the many biological multitudes that are integrated with or co-exist in our porous bodies.

COVID-19 resembles the philosopher Jean-Luc Nancy's intruder: “The intruder enters by force, through surprise or ruse, in any case without the right and without having first been admitted" (p. 1). ${ }^{1}$ Nancy's intruder is a transplanted heart, which produces all kinds of unwelcomed strangeness. The first being his own original and untimely heart that betrayed him: an intruder from the inside out. His own system has failed him. Then there is the intrusion of a foreign heart, which the rest of his body may reject. To prevent this, his body becomes connected to all types of machinery and surveillance, his survival now dependent on strangers and strangeness. Such an open wound is never reconciled. There is no 'new normal' from such intrusion, only a multiplying of strangeness. This radical exposure-the cutting open of one's chest, the removal of one's heart, the suturing back together of an intruded-upon bodydraws attention not only to foreign organs and the strangeness of one's own body, but also to the entire host of problematic lifeforms already inside us. Nancy is warned of the dangers posed to his weakened immunity system by the outside world - "the crowds, stores, swimming pools, small children, those who are sick" (p. 9). ${ }^{1}$ But it is not the outside world that is of the greatest concern for Nancy. Once dormant diseases, "the old viruses that have always been lurking in the shadow of my immune system - life-long intrus [intruders], 


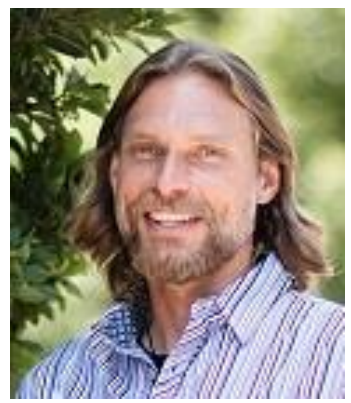

as they have always been there" (p. 9) surface and are set against him. ${ }^{1}$

There is the basic existential trauma of being human; each of us are multiple thanks to our bodies, egos, languages and cultures. However, Nancy's intrusion throws him into a different form of trauma, where the technical and the personal reach another level of multiplicity and interdependency. His individual traumatic event is part of how historically humanity has been striving for survival and immortality by aiming at "mastery and possession of nature" (p. 6). ${ }^{1}$ This different level of intruder-trauma that expands and multiplies othering, which Nancy experienced personally, is now being experienced collectively by the world of hospitality through the coronavirus pandemic.

Nancy's intruder is an apt metaphor that helps us to reflect on pandemichospitality. Our hospitality industry is bewildered, contemplating the taking over by a radical untamed stranger. We are left asking: What hospitality is possible with the intruder within? We are mourning the loss of the hospitality that was, which assimilated and welcomed the stranger into becoming us. Today, we encounter the science-fiction-like hospitality of warning signs, bio-technical controls, monitoring and prevention. The pandemic intruder attunes us to a world of hospitality as fragmented, put-together, patched, cyborg-like and dependent on multiple others in myriad new ways. Hospitality is now "more double or multiple than ever" (p. 4). ${ }^{1}$ Like the intruder-hospitality paradox of the sign at a COVID-19 testing facility - "Stay apart. Take care of each other" - what new possibilities emerge if we reimagine hospitality as being connected but at a distance, being together though never fully united? Perhaps in the chaotic multiplicity of the hospitality of intrusion, there is hospitality as the art, not of the becoming and knowing of the other, but of the humble surrendering to the excessive uncontrollable otherness of the world.

The original publication on which this article is based is available here: https://muse.jhu.edu/article/38170/summary

\section{Corresponding author}

Ana María Munar can be contacted at anm.mpp@cbs.dk.

\section{References}

(1) Nancy, J. (2002 [2000]). L'Intrus. (S. Hanson, Trans.). East Lansing, Michigan: Michigan State University Press. 